\title{
Energy storage materials with oxide-encapsulated inclusions of low melting metal
}

\author{
Ani Abraham, Mirko Schoenitz, Edward L. Dreizin \\ New Jersey Institute of Technology, Newark, NJ
}

\begin{abstract}
A composite energy storage material (ESM) with inclusions of a low-melting point metal encapsulated in protective metal oxide shells is prepared and characterized. ESM precursor is a metal matrix composite with metal oxide inclusions. Controlled redox reaction between the matrix and inclusions yields a composite with inclusions of an oxide encapsulated, easy to melt metal. $\mathrm{Al} / \mathrm{Bi}_{2} \mathrm{O}_{3}$ nanocomposite thermites served as precursors for $\mathrm{ESM}$ with $\mathrm{Al}$ matrix and $\mathrm{Bi}$ inclusions encapsulated with $\mathrm{Al}_{2} \mathrm{O}_{3}$. Thermal and mechanical properties of the ESM were compared to those of reference binary $\mathrm{Al} / \mathrm{Bi}$ and ternary $\mathrm{Al} / \mathrm{Bi} / \mathrm{Al}_{2} \mathrm{O}_{3}$ materials. The material containing encapsulated $\mathrm{Bi}$ inclusions stored energy by melting and solidifying $\mathrm{Bi}$ inclusions repeatedly. The inclusions did not drift upon heating; composite structure remained largely intact upon thermal cycling. Conversely, the structure of reference materials with similar compositions but without encapsulated Bi inclusions was not preserved upon thermal cycling. Molten Bi tended to separate from $\mathrm{Al}$ and form coarse network of inclusions. Upon cycling, Bi accumulated on surface of the material. Difference in mobility between encapsulated and nonencapsulated $\mathrm{Bi}$ inclusions caused differences in the mechanical properties of the composites. Materials with encapsulated $\mathrm{Bi}$ inclusions were much stronger and capable of retaining their structure and strength despite thermal cycling.
\end{abstract}

Keywords: metal composite; high thermal conductivity; phase change materials 


\section{Introduction}

Metal based energy storage materials (ESM) have advantages of high thermal conductivity, potentially high strength, and others [1]. The main issue is that the metal that melts upon heating (and thus serves as an energy storage medium) needs to be contained in order for the material to be used in repetitive heating cycles. Containment of liquid metals is difficult; often bulk containers are used [2], which limit significantly the types of structures that can be manufactured using the ESM. Using couples of metals that do not form intermetallics, such as Ag/Bi was reported recently [3]; however, such systems are limited and even if no intermetallics are formed, inclusions of an easily melting metal (Bi) are expected to migrate and coalesce after thermal cycling.

Composite materials can be readily prepared, in which a low-melting point metal is dispersed in a metal or ceramic matrix with a higher melting point. However, without encapsulation of the low-melting point metal inclusions, the material becomes structurally weak when the lowmelting metal is liquid, and therefore deteriorates rapidly. Repeated heating may additionally cause formation of alloys and other compounds, altering the melting point of inclusions and thus affecting their energy storage capacity. Further, repeated melting may cause redistribution of non-encapsulated material within the structure, causing loss of uniformity. Finally, the strength of the composite material containing low-melting point inclusions would be reduced dramatically when the inclusions melt. The above negative effects can be circumvented if inclusions of the low-melting point material are encapsulated in a matrix that is thermally stable and mechanically sound.

In the structures described here, the energy storing medium (an easy to melt metal or alloy) is enclosed in nano-scale inclusions or layers surrounded by protective metal oxide. Such 
structures are stable in time and are not destroyed by repeated melting and solidification of the encapsulated inclusions.

\section{Technical Approach}

The ESM is made using a precursor material, a nanocomposite thermite powder prepared by arrested reactive milling [4]. Alternatively, it may be a nanocomposite layered structure prepared by vacuum deposition. The preparation of the energy storage material by milling and its structure are illustrated schematically in Fig. 1. Starting materials for the milling are regular powders, one of which is a metal, such as aluminum, and another is a readily reducible metal oxide. For ESM, the reduced oxide should yield an easily melting metal; examples include oxides of bismuth, indium, tin, and others. After milling, a fully dense composite is prepared with the metal matrix and oxide inclusions. Typically, the dimensions of inclusions are close to $100 \mathrm{~nm}$ [5]. Using a highly heat conductive aluminum as the metal matrix ensures the capability to reduce nearly all metal oxides. Other metal fuels that can be used with many oxides include magnesium, zirconium, and titanium. Different metal/oxide combinations can be used to prepare the ESM capable of storing energy at different temperatures and having tunable thermal conductivity and heat capacity.

To prepare the energy storage material, the nanocomposite material prepared by milling is heated up slowly so that the redox reaction between the metal matrix and oxide inclusions occurs. The heating should be well controlled so that the reaction occurs heterogeneously and the structure of the composite material is retained. For example, maintaining the temperature below the melting point of the metal matrix will help stabilize the structure. As a result of the redox reaction, each oxide inclusion is reduced to its respective metal surrounded by a layer of the product oxide. For 
the example of aluminum matrix and bismuth oxide inclusions, the product will be bismuth metal inclusions encapsulated in aluminum oxide. The encapsulated bismuth inclusions will be inside a metal matrix for fuel rich compositions. For compositions close to stoichiometry, the matrix will be primarily made of the formed oxide. For tin oxide inclusions in aluminum matrix, the product will be tin inclusions encapsulated in aluminum oxide. Once produced, such encapsulated metal inclusions can be heated above the melting point of the encapsulated metal, e.g., $\mathrm{Bi}$. The metal will remain within the protective oxide shell (e.g., $\mathrm{Al}_{2} \mathrm{O}_{3}$ shell) and will be capable of melting and solidifying repeatedly, without changing the overall material structure or morphology. The continuity and structure of the matrix will be unaffected by melting of encapsulated inclusions. Thus, the desired energy storage material is produced.

Properties of the nanocomposite energy storage material derived from energetic nanocomposites can be adjusted by changing the original metal/oxide ratio: compositions closer to the stoichiometry of the redox reaction will produce more metal (e.g. Bi), as well as more product oxide (e.g. alumina). The resulting energy storage material has therefore a higher energy storage capacity, and it is mechanically stronger. Its bulk thermal conductivity will be lower, however. More metal-rich energetic composites will result in energy storage materials with less product metal (lower energy storage capacity), less product oxide (lower mechanical strength), and more residual metal (higher thermal conductivity). This gives the opportunity to tailor the material to specific applications. 


\section{Experimental and Instrumentation Techniques}

\subsection{Material synthesis}

Bismuth inclusions serve as melting energy-storing medium in the materials described here. Selecting bismuth is justified by earlier studies of $\operatorname{ESM}[3,6]$. Starting materials used to prepare fuel rich $\mathrm{Al} / \mathrm{Bi}_{2} \mathrm{O}_{3}$ nanocomposite were elemental aluminum powder, -325 mesh $(<45 \mu \mathrm{m})$, 99.5\% pure, from Atlantic Equipment Engineers and fine powder of bismuth oxide, 99\% pure, from Skylighter, Inc. The powders were mixed to produce two different compositions, with 6 and 12 moles of $\mathrm{Al}$ per mole of $\mathrm{Bi}_{2} \mathrm{O}_{3}$, designated respectively as $6 \mathrm{Al} / \mathrm{Bi}_{2} \mathrm{O}_{3}$ and $12 \mathrm{Al} / \mathrm{Bi}_{2} \mathrm{O}_{3}$. The blended powders were ball-milled under inert argon gas environment using a shaker mill (SPEX Certiprep, 8000 series) with two $50 \mathrm{~mL}$ flat-ended steel vials cooled by room-temperature air jets. Case-hardened carbon steel balls $3 / 8$ "-diameter, were used as a milling media. Ball to powder mass ratio (BPR) was fixed at 10. During milling, $3 \mathrm{~mL}$ of hexane was used as the process control agent (PCA). Milling time was set to $45 \mathrm{~min}$.

Nanocomposite powders, consisting of fully dense individual particles obtained by ball milling $[7,8]$, were used to prepare two types of ESM samples. For thermal analysis, the powders were pressed into 1/8-inch diameter pellets with a uniaxial die at a force of $1000 \mathrm{lbs}$ using a Carver automatic pellet press in room air. Although not quantified, pervious experience shows negligible amount of air may have been trapped inside during pelletizing at these conditions [9]. The pellets were heated in a furnace of a thermal analyzer (Netzsch STA409 PG) in argon to obtain bismuth inclusions encapsulated in aluminum oxide. The pellets were heated to $550{ }^{\circ} \mathrm{C}$ and $300{ }^{\circ} \mathrm{C}$ and were held at the maximum temperature for 6 and $64 \mathrm{hrs,} \mathrm{respectively.} \mathrm{For}$ mechanical testing, -inch pellets were prepared using the same pellet press and annealed at 300 ${ }^{\circ} \mathrm{C}$ for 5 days using an Omegalux LMF-3550 box furnace under inert argon gas environment. 
Any air trapped within the pellet at the particle-particle interfaces, may react with the Al-rich surface of the particle to form $\mathrm{Al}_{2} \mathrm{O}_{3}$ during annealing under inert argon gas environment. However, this should only add additional barrier to prevent molten Bi migration and should not be in contact with the reduced $\mathrm{Bi}$ during the redox reaction, which occur inside the particle. From previous experience [9], pelletizing conditions described above, may only lead to 10 to $20 \%$ of porosity, which should not cause any differences to the finally formed ESM structure.

For comparison, two additional composites were prepared. One reference material was used to observe the effect of encapsulation of Bi inclusions on its re-melting as a result of cycled heating. It consisted of a binary composite of $\mathrm{Al}$ and $\mathrm{Bi}$ with 6.5 moles of $\mathrm{Al}$ per mole of $\mathrm{Bi}$ : 6.5 $\mathrm{Al} / \mathrm{Bi}$. It was also used to compare mechanical properties of different materials. The second material was used as a more appropriate reference for mechanical properties of the prepared material and included $\mathrm{Al}_{2} \mathrm{O}_{3}$ as well, which could cause dispersion strengthening. It consisted of a ternary $\mathrm{Al}, \mathrm{Al}_{2} \mathrm{O}_{3}$ and $\mathrm{Bi}$ composite, with mole composition of $4 \mathrm{Al} / \mathrm{Al}_{2} \mathrm{O}_{3} / 2 \mathrm{Bi}$. The specific compositions $6.5 \mathrm{Al} / \mathrm{Bi}$ and $4 \mathrm{Al} / \mathrm{Al}_{2} \mathrm{O}_{3} / 2 \mathrm{Bi}$ were selected to fix the bismuth volume fraction of the $\mathrm{Al} / \mathrm{Bi}$ and $\mathrm{Al} / \mathrm{Al}_{2} \mathrm{O}_{3} / \mathrm{Bi}$ composites to mimic the expected bismuth volume fraction in the encapsulated ESM produced using $12 \mathrm{Al} / \mathrm{Bi}_{2} \mathrm{O}_{3}$ and $6 \mathrm{Al} / \mathrm{Bi}_{2} \mathrm{O}_{3}$ nanocomposite powders, respectively. Both reference composites were prepared using the same elemental aluminum as used to prepare $\mathrm{Al} / \mathrm{Bi}_{2} \mathrm{O}_{3}$ nanocomposite powders, elemental bismuth powder, $99.5 \%$ pure, -325 mesh from Alfa Aesar, and $\alpha$-aluminum oxide nano powder, $99.85 \%$ pure, APS $150 \mathrm{~nm}$, from Inframat Advanced Materials. The blended $\mathrm{Al} / \mathrm{Bi}$, and $\mathrm{Al} / \mathrm{Bi} / \mathrm{Al}_{2} \mathrm{O}_{3}$ powders used for different reference materials were ball milled using the same conditions as described above. The milling times were 45 minutes for $4 \mathrm{Al} / \mathrm{Al}_{2} \mathrm{O}_{3} / 2 \mathrm{Bi}$, and 60 minutes for $6.5 \mathrm{Al} / \mathrm{Bi}$. Pellets with diameters 1/8 and 1/4-inch were pressed for thermal analysis and mechanical tests, respectively. 


\subsection{Characterization Techniques}

The particle and inclusion sizes, shapes, and morphology of both, as-prepared and reacted materials were characterized using back-scattered scanning electron microscopy (SEM) using a LEO 1530 Field Emission microscope. Since backscattered electrons are sensitive to the phase contrast between elements with different atomic weights, bismuth appears brighter than aluminum in the images.

Thermal stability and temperature-dependent phase changes were analyzed using differential scanning calorimetry (DSC). A Netzsch Simultaneous Thermal Analyzer STA409 PG with a DSC sample carrier and corundum sample crucibles was used to conduct the experiments in ultra-high purity argon $(50 \mathrm{~mL} / \mathrm{min})$ environment at a heating rate of $10^{\circ} \mathrm{C} / \mathrm{min}$.

The thermal stability and latent heat storage of the reacted materials (PCM) were analyzed in the DSC by cycling the annealed samples between $50{ }^{\circ} \mathrm{C}$ and $300{ }^{\circ} \mathrm{C}$ for 5 times. The thermal energy storage due to the melting of $\mathrm{Bi}$, and the onset temperature of the melting peak was obtained for each cycle.

Using an Instron 5567 universal testing system equipped with a furnace, two different types of mechanical testing were conducted on the consolidated pellets. First, stress-strain curves were recorded at constant temperatures of $250{ }^{\circ} \mathrm{C}$ and $300{ }^{\circ} \mathrm{C}$, selected to be respectively below and above the Bi melting point. These isothermal tests were performed for the annealed $12 \mathrm{Al}^{1} / \mathrm{Bi}_{2} \mathrm{O}_{3}$ and $6.5 \mathrm{Al} / \mathrm{Bi}$ pellets. A compressive stress-strain curve and strength at $5 \%$ strain as function of temperature were obtained. In addition, creep tests at a constant load of $3 \mathrm{kN}$ were performed where the temperature was scanned from 200 to $300^{\circ} \mathrm{C}$. The strain as function of temperature was recorded; the test was performed for annealed $6 \mathrm{Al} / \mathrm{Bi}_{2} \mathrm{O}_{3}$ and $4 \mathrm{Al} / \mathrm{Al}_{2} \mathrm{O}_{3} / 2 \mathrm{Bi}$. The 
temperature was scanned by changing the furnace setpoint, which resulted in a nonlinear heating profile. The actual sample temperature was estimated from baseline creep tests, assuming initial and final stable states represent the respective temperature setpoints.

\section{Results and Discussion}

\subsection{Preparation of composite material with encapsulated bismuth inclusions}

DSC traces for 1/8-inch diameter pellets of milled $12 \mathrm{Al} / \mathrm{Bi}_{2} \mathrm{O}_{3}$, and $6.5 \mathrm{Al} / \mathrm{Bi}$ composites are shown in Fig. 2. The samples were heated at $10{ }^{\circ} \mathrm{C} / \mathrm{min}$ to $550{ }^{\circ} \mathrm{C}$, well above the melting point of pure bismuth. For $12 \mathrm{Al} / \mathrm{Bi}_{2} \mathrm{O}_{3}$ pellet, the DSC signal shows a broad exothermic peak overlapping with a weak endothermic peak near the melting point of pure bismuth metal. The exothermic reaction indicates reduction of $\mathrm{Bi}_{2} \mathrm{O}_{3}$ and oxidation of $\mathrm{Al}$. By the time the $\mathrm{Bi}$ melting point is reached, a small amount of Bi has formed, causing a small endothermic peak overlapping with the broader exothermic peak. In contrast, as expected for the $6.5 \mathrm{Al} / \mathrm{Bi}$ pellet, the DSC signal shows only an endothermic peak, indicating melting of Bi.

Backscattered electron SEM images of cross-sectioned pellets for as-milled and annealed $12 \mathrm{Al} / \mathrm{Bi}_{2} \mathrm{O}_{3}$ and $6.5 \mathrm{Al} / \mathrm{Bi}$ materials are shown in Fig. 3. Annealed materials were heated to 300 ${ }^{\circ} \mathrm{C}$, held at that temperature for 64 hours, and then cycled between 200 and $300{ }^{\circ} \mathrm{C}$ for five times. For as-milled $12 \mathrm{Al} / \mathrm{Bi}_{2} \mathrm{O}_{3}$, light-colored micron- and nano-sized inclusions of $\mathrm{Bi}_{2} \mathrm{O}_{3}$ are embedded into a dark-grey Al matrix. After the material is annealed, it is observed that fine light-colored inclusions remain uniformly distributed in the material. Their dimensions remain close to those of the original $\mathrm{Bi}_{2} \mathrm{O}_{3}$ inclusions. The boundaries and shapes of inclusions change, but no coalescence or migration of inclusions within the sample are detected. The inclusions 
formed after annealing are mostly composed of $\mathrm{Bi}$. Encapsulating $\mathrm{Al}_{2} \mathrm{O}_{3}$ cannot be distinguished from the $\mathrm{Al}$ matrix. Only amorphous $\mathrm{Al}_{2} \mathrm{O}_{3}$ is expected to form in samples exposed to $300{ }^{\circ} \mathrm{C}$ and $550^{\circ} \mathrm{C}[10]$. Such $\mathrm{Al}_{2} \mathrm{O}_{3}$ layers are nonporous, when formed in absence of an aluminadissolving solvent [11] and thus should prevent migration of the Bi inclusions.

For as-milled $6.5 \mathrm{Al} / \mathrm{Bi}$, the structure is very homogeneous and only nano-scaled inclusions of $\mathrm{Bi}$ are observed. After annealing, however, the structure changes substantially. Bismuth is redistributed to form a relatively coarse, interconnected web-like structure. Further, bismuth migrates to the surface of the sample pellet, forming a Bi-rich layer. This behavior is consistent with phase separation occurring in similar alloys upon heating [12]. The phase separation is due to a combination of the Marangoni and Stokes motions. No such redistribution was detected for the material prepared using $12 \mathrm{Al} / \mathrm{Bi}_{2} \mathrm{O}_{3}$ nanocomposite as precursor and producing encapsulated nano-sized $\mathrm{Bi}$ inclusions. It is expected that after continuing thermal cycling, the $6.5 \mathrm{Al} / \mathrm{Bi}$ metal-metal composite will become mechanically weaker as more and more bismuth metal will concentrate at the outside of the pellet. The composite structure would further coarsen limiting practical usefulness of such material as ESM.

\subsection{Energy storage performance}

DSC traces for both ESM prepared using $12 \mathrm{Al} / \mathrm{Bi}_{2} \mathrm{O}_{3}$ and for reference $6.5 \mathrm{Al} / \mathrm{Bi}$ samples are shown in Fig. 4. For each material, two samples were used in experiments: annealed at 550 and $300{ }^{\circ} \mathrm{C}$ for 6 and $64 \mathrm{hrs}$, respectively. For clarity, the traces for materials annealed at different temperatures are shifted vertically relative to each other. For both $12 \mathrm{Al} / \mathrm{Bi}_{2} \mathrm{O}_{3}$, and $6.5 \mathrm{Al} / \mathrm{Bi}$, an endothermic peak is observed near the pure Bi melting point. The peak onset temperatures and 
respective integrated heat effects are listed in Table 1. In addition, the heat effects estimated based on the total available amount of Bi for each material are shown.

The peaks occur at a slightly lower temperature, are slightly broader and less deep for the ESM prepared using $12 \mathrm{Al} / \mathrm{Bi}_{2} \mathrm{O}_{3}$. For this material, the peak comprises two closely overlapping endothermic events, particularly well seen for the sample annealed at $300{ }^{\circ} \mathrm{C}$. The double peak may indicate dissolution of very small amount of aluminum in bismuth. The Bi-rich part of the Al-Bi phase diagram is not well quantified and the eutectic composition contains more than 99 at- $\%$ of $\mathrm{Bi}$ [13]. Eutectic melting occurs at $270{ }^{\circ} \mathrm{C}$, very close to the melting point of pure $\mathrm{Bi}$, $271.442{ }^{\circ} \mathrm{C}$. If the amount of dissolved $\mathrm{Al}$ is less than that of the eutectic composition, the melting peak is expected to split into two closely located peaks, similar to what is observed in Fig. 4(A). However, if the amount of dissolved Al exceeds that of the eutectic composition, only the eutectic melting peak should be detectable in the present experiments. The liquidus line for the remaining, Al-rich solution will be at a much higher temperature, which was not reached in the present DSC tests. Because of the dissolved aluminum, the enthalpy of melting may exceed the melting enthalpy of pure Bi, as observed in Fig. 4(B).

The melting peak onset temperatures are slightly lower for the ESM with encapsulated Bi inclusions compared to those for the binary $\mathrm{Al} / \mathrm{Bi}$ material. It likely is associated with reduced dimensions of the $\mathrm{Bi}$ inclusions, so that the effect of melting point depression for nano-sized bismuth domains becomes noticeable $[3,6]$.

The enthalpy of melting is consistently greater for the samples annealed at a higher temperature for both ESM with encapsulated Bi inclusions and for the reference material. For the ESM prepared using a nanocomposite thermite, the effect is most likely caused by a more complete 
reduction of $\mathrm{Bi}_{2} \mathrm{O}_{3}$ at elevated temperatures. Conversely, for the reference metal-metal composite, the effect is likely caused by a more significant dissolution of aluminum in the molten bismuth upon its heating to higher temperatures.

\subsection{Mechanical Testing}

Traces of stress as a function of strain for the isothermal mechanical loading tests are shown in Fig. 5 for annealed $12 \mathrm{Al} / \mathrm{Bi}_{2} \mathrm{O}_{3}$ and $6.5 \mathrm{Al} / \mathrm{Bi}$ samples. Compressive stress-strain curves were recorded at $250{ }^{\circ} \mathrm{C}$ and $300{ }^{\circ} \mathrm{C}$, below and above the Bi melting point of $271.442{ }^{\circ} \mathrm{C}$, respectively. Both materials deform elastically initially, until the yield strength is reached, after which plastic deformation starts. The ESM with encapsulated Bi inclusions prepared using a nanocomposite thermite is generally stronger than the metal composite. Both materials show a reduction in yield strength above the Bi melting point. At $5 \%$ strain, the softening of the encapsulated composite amounts to a $15.6 \%$ reduction in strength, while the strength of the metal composite decreases by $31.3 \%$. This suggests that the encapsulation of $\mathrm{Bi}$ in the molten state results in a material that is mechanically more sound, and less likely to deteriorate at prolonged or repeated exposure to temperatures above the melting point.

Strain measured in creep tests, when the samples were loaded with a constant force of $3 \mathrm{kN}$ and heated up to $300^{\circ} \mathrm{C}$ is shown in Fig. 6. The results are shown for the ESM prepared using nanocomposite thermite $6 \mathrm{Al} / \mathrm{Bi}_{2} \mathrm{O}_{3}$ and for reference ternary composite material $4 \mathrm{Al} / \mathrm{Al}_{2} \mathrm{O}_{3} / 2 \mathrm{Bi}$ annealed preliminarily at $300{ }^{\circ} \mathrm{C}$ for $120 \mathrm{hrs}$. It is observed that the reference ternary material begins deforming at about $230^{\circ} \mathrm{C}$ as the $\mathrm{Bi}$ component starts to soften. Near the melting point of $\mathrm{Bi}$, dramatic deformation occurs. Conversely, the ESM containing encapsulated Bi inclusions does not show an appreciable deformation in the entire temperature range considered. 
SEM images of mechanically tested samples are shown in Fig 7 for the encapsulated materials prepared from $12 \mathrm{Al} / \mathrm{Bi}_{2} \mathrm{O}_{3}$ and $6 \mathrm{Al} / \mathrm{Bi}_{2} \mathrm{O}_{3}$ and the non-encapsulated materials, $6.5 \mathrm{Al} / \mathrm{Bi}$ and $4 \mathrm{Al} / \mathrm{Al}_{2} \mathrm{O}_{3} / 2 \mathrm{Bi}$. For both materials containing encapsulated Bi shown in Figs. $7 \mathrm{~A}$ and $\mathrm{C}$, the bright $\mathrm{Bi}$ inclusions appear to be roughly equiaxial and uniformly dispersed in the darker Al-rich matrix. As in Fig. 3, it is difficult to detect $\mathrm{Al}_{2} \mathrm{O}_{3}$. For the material with greater $\mathrm{Bi}$ concentration (Fig. 7C), the Bi inclusions are greater in size and occupy a greater fraction of the material's volume. For both materials containing non-encapsulated $\mathrm{Bi}$, bright $\mathrm{Bi}$ inclusions form interconnected networks. It is interesting to compare structures shown in Fig 7C and 7D, which have similar concentrations of $\mathrm{Al}, \mathrm{Bi}$, and $\mathrm{Al}_{2} \mathrm{O}_{3}$. Clear morphological differences between the two materials are observed. In Fig 7D, crystalline $\mathrm{Al}_{2} \mathrm{O}_{3}$ particles are visible. Such particles are well separated from one another and are surrounded by interconnected Bi metal matrix. In contrast, the $\mathrm{Al}_{2} \mathrm{O}_{3}$ is hard to detect in Fig $7 \mathrm{C}$; however, multiple separated $\mathrm{Bi}$ inclusions are observed instead. Most of the Bi inclusions have well-defined boundaries surrounded by a darker phase, which is expected to be $\mathrm{Al}_{2} \mathrm{O}_{3}$ and $\mathrm{Al}$.

\section{Conclusions}

Energy storage materials containing inclusions of an easy-to melt metal, Bi, encapsulated with protective $\mathrm{Al}_{2} \mathrm{O}_{3}$ in an aluminum matrix were prepared using nanocomposite $\mathrm{Al} / \mathrm{Bi}_{2} \mathrm{O}_{3}$ thermite as a precursor material. The precursor material was slowly annealed to reduce $\mathrm{Bi}_{2} \mathrm{O}_{3}$ and form encapsulated $\mathrm{Bi}$ inclusions. The material is shown to be capable of storing energy by melting and solidifying Bi inclusions. The inclusions do not drift inside the material upon heating; prepared composite structure remains largely intact upon thermal cycling. Conversely, the structure of reference composite materials with similar bulk compositions but without encapsulated $\mathrm{Bi}$ inclusions is not preserved upon thermal cycling. Molten Bi tends to separate 
from $\mathrm{Al}$ and form interconnected coarse network of inclusions. Upon cycling, Bi accumulates on surface of the material. Difference in mobility between encapsulated and non-encapsulated Bi inclusions causes dramatic differences in the mechanical properties of the resulting composites. Materials with encapsulated Bi inclusions are much stronger and capable of retaining their structure and strength despite thermal cycling expected for useful energy storage materials.

\section{Acknowledgement}

This work was sponsored by the US Defense Threat Reduction Agency.

\section{References}

[1] H. Ge, H. Li, S. Mei, J. Liu. Low melting point liquid metal as a new class of phase change material: An emerging frontier in energy area, Renewable Sustainable Energy Rev. 21 (2013) 331-346.

[2] A.J. Spero, F.S. Wyle. Design of high energy density thermal storage device. US20110308762A1: Thermal Storage Systems, USA . 2011. p.12 pp.

[3] M. Liu, Y. Ma, H. Wu, R.Y. Wang. Metal matrix-metal nanoparticle composites with tunable melting temperature and high thermal conductivity for phase-change thermal storage, ACS Nano 9 (2015) 1341-1351.

[4] E.L. Dreizin, M. Schoenitz. Nano-composite energetic powders prepared by arrested reactive milling. US Patent 7,524,355 2009.

[5] R.A. Williams, M. Schoenitz, E.L. Dreizin. Validation of the thermal oxidation model for Al/CuO nanocomposite powder, Combustion Science and Technology 186 (2014) 47-67.

[6] M. Liu, R.Y. Wang. Phase change nanocomposites with tunable melting temperature and thermal energy storage density, Nanoscale 5 (2013) 7234-7237.

[7] M. Schoenitz, T.S. Ward, E.L. Dreizin. Fully dense nano-composite energetic powders prepared by arrested reactive milling, Proceedings of the Combustion Institute 30 (2005) 2071-2078.

[8] C. Suryanarayana. Mechanical alloying and milling, Progress in Materials Science 46 (2001) 1184.

[9] D. Stamatis, X. Zhu, M. Schoenitz, E.L. Dreizin, P. Redner. Consolidation and mechanical properties of reactive nanocomposite powders, Powder Technology 208 (2011) 637-642.

[10] A.L. Dragoo, J.J. Diamond. Transitions in Vapor-Deposited Alumina from $300^{\circ}$ to $1200^{\circ} \mathrm{C}$, Journal of the American Ceramic Society 50 (1967) 568-574.

[11] I. Levin, D. Brandon. Metastable Alumina Polymorphs: Crystal Structures and Transition Sequences, Journal of the American Ceramic Society 81 (1998) 1995-2012.

[12] R. Dai, S. Zhang, X. Guo, J. Li. Formation of core-type microstructure in Al-Bi monotectic alloys, Materials Letters 65 (2011) 322-325.

[13] H. Okamoto. Supplemental Literature Review of Binary Phase Diagrams: Al-Bi, Al-Dy, Al-Gd, AlTb, C-Mn, Co-Ga, Cr-Hf, Cr-Na, Er-H, Er-Zr, H-Zr, and Ni-Pb, J. Phase Equilib. Diffus. 35 (2014) 343-354. 


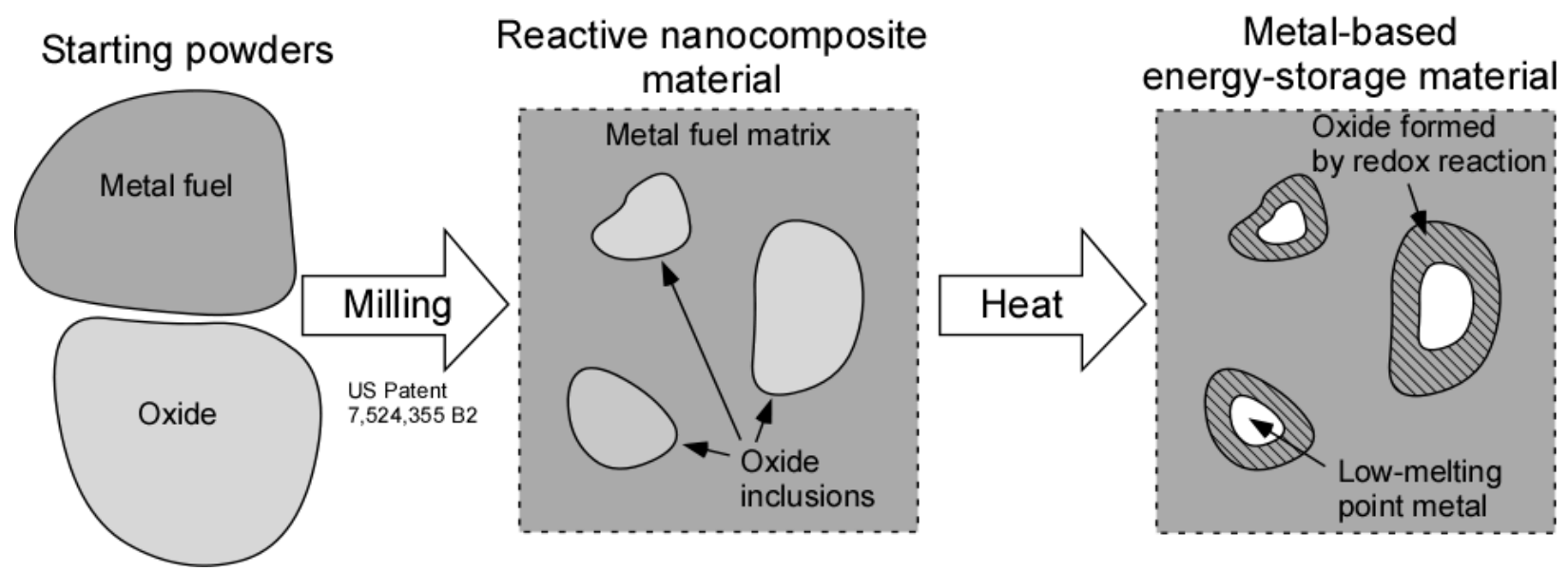

Figure 1. Schematic diagram showing preparation of the metal-based energy storage material and its structure.

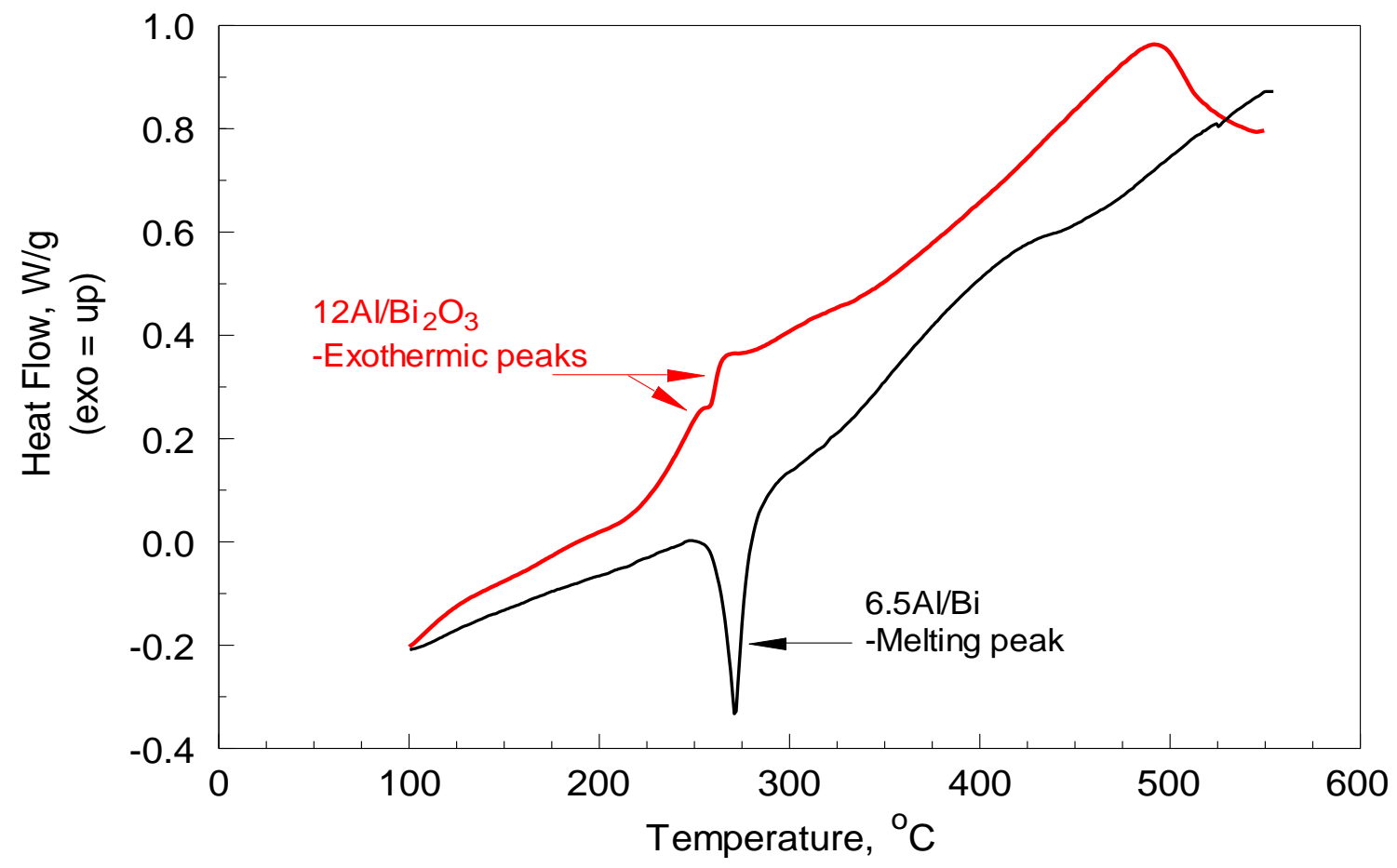

Figure 2. DSC signal of $12 \mathrm{Al}^{-} / \mathrm{Bi}_{2} \mathrm{O}_{3}$ nanocomposite and $6.5 \mathrm{Al} / \mathrm{Bi}$ metal-metal composite heated to $550^{\circ} \mathrm{C}$ at $10^{\circ} \mathrm{C} / \mathrm{min}$. 

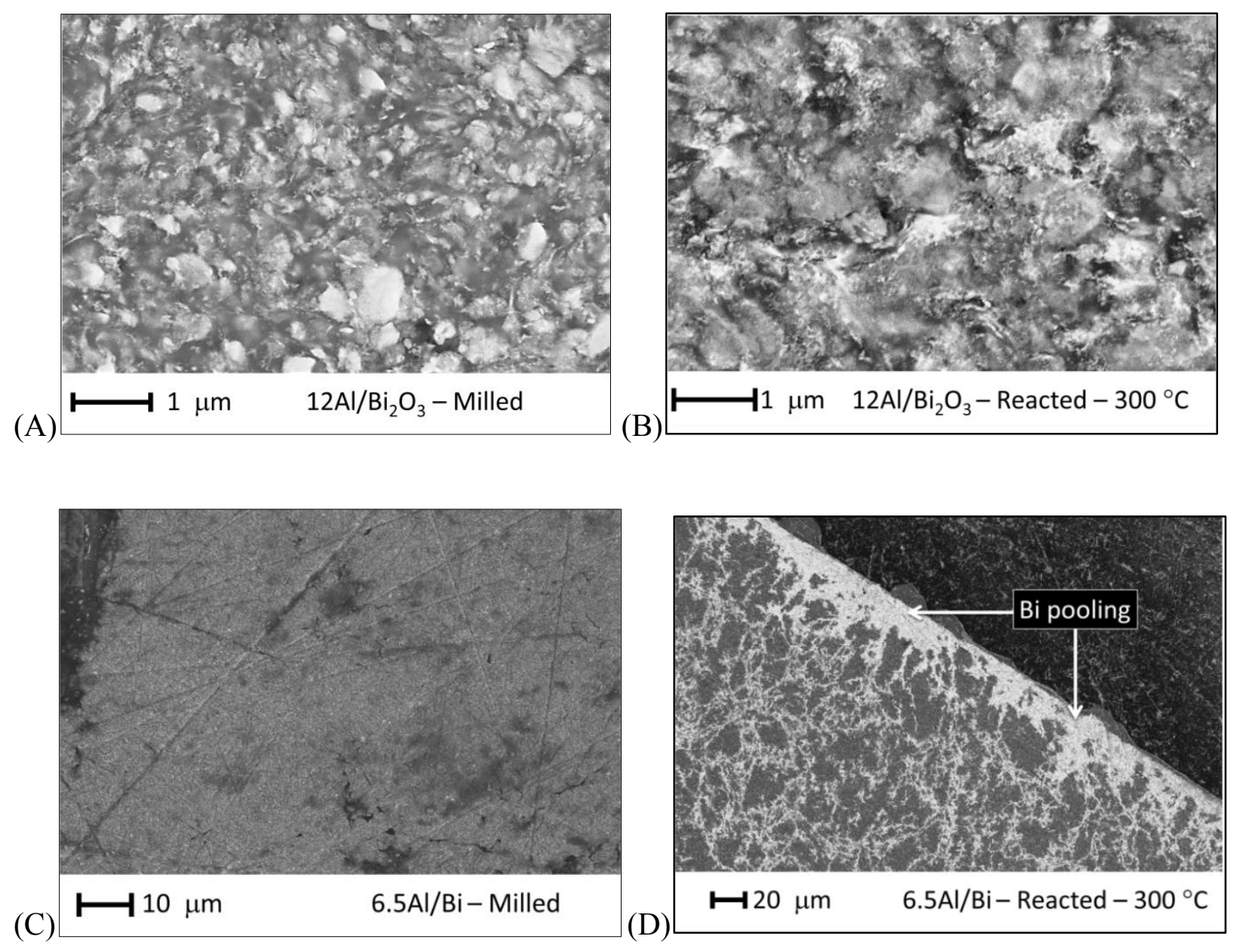

Figure 3. Backscattered electron cross-sectional SEM image of (A) 12 $\mathrm{Al} / \mathrm{Bi}_{2} \mathrm{O}_{3}$ metal-metal oxide nanocomposite as milled (B) $12 \mathrm{Al} / \mathrm{Bi}_{2} \mathrm{O}_{3}$ pellet annealed at $300{ }^{\circ} \mathrm{C}$ and held at isothermal for $64 \mathrm{~h}$ before cycled for 5 times (C) 6.5Al/Bi metal-metal composite as milled (D) 6.5Al/Bi pellet annealed at $300^{\circ} \mathrm{C}$ and held at isothermal for $64 \mathrm{~h}$ before cycled for 5 times and evidence of Bi metal pooling to the outer surface is observed. 


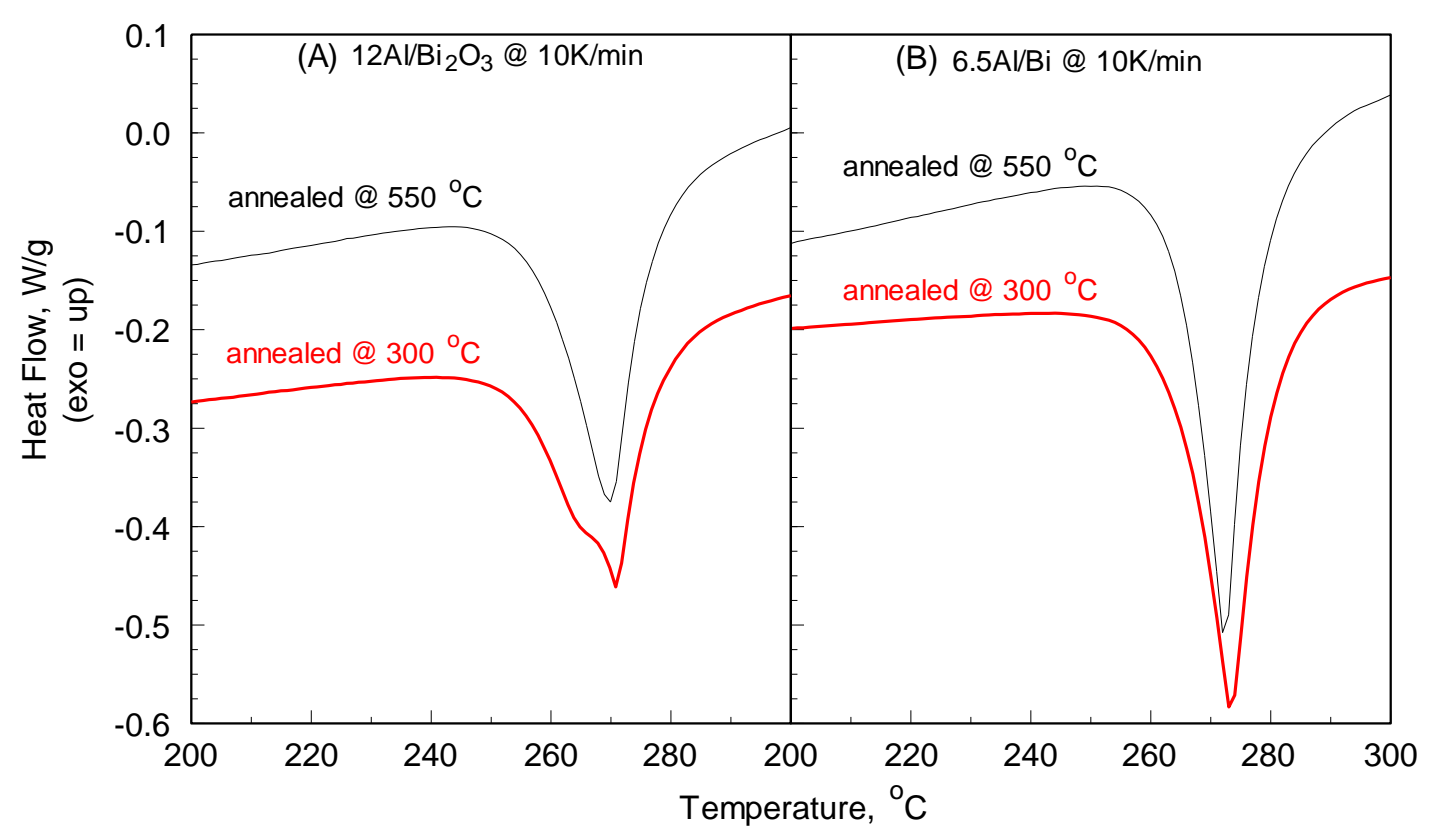

Figure 4. DSC signal of $12 \mathrm{Al} / \mathrm{Bi}_{2} \mathrm{O}_{3}$ nanocomposite and $6.5 \mathrm{Al} / \mathrm{Bi}$ metal-metal composite annealed at $550{ }^{\circ} \mathrm{C}$ and $300{ }^{\circ} \mathrm{C}$ for $6 \mathrm{hrs}$ and $64 \mathrm{hrs}$, respectively, and heated a second time to $300{ }^{\circ} \mathrm{C}$. 


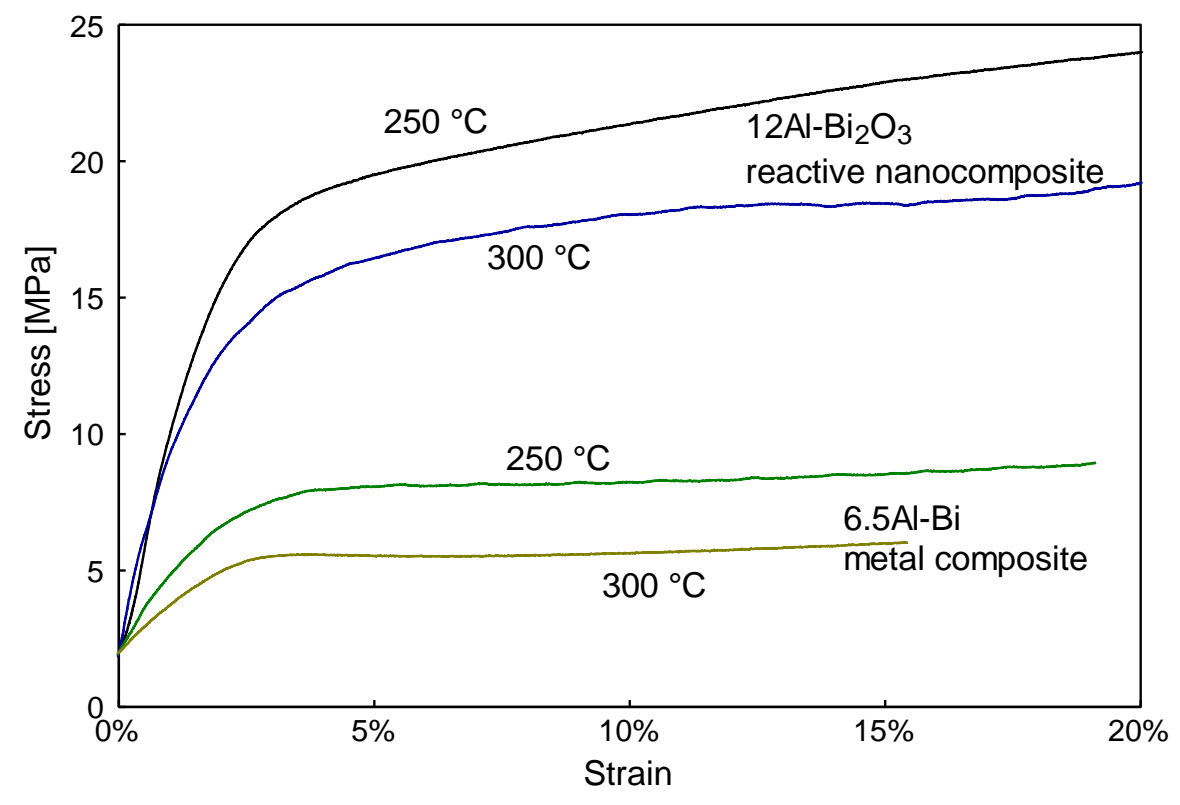

Figure 5. Stress-strain curves of $1 / 4$-inch pellets of a $12 \mathrm{Al} / \mathrm{Bi}_{2} \mathrm{O}_{3}$ metal-metal oxide nanocomposite, and a $6.5 \mathrm{Al} / \mathrm{Bi}$ metal-metal composite.

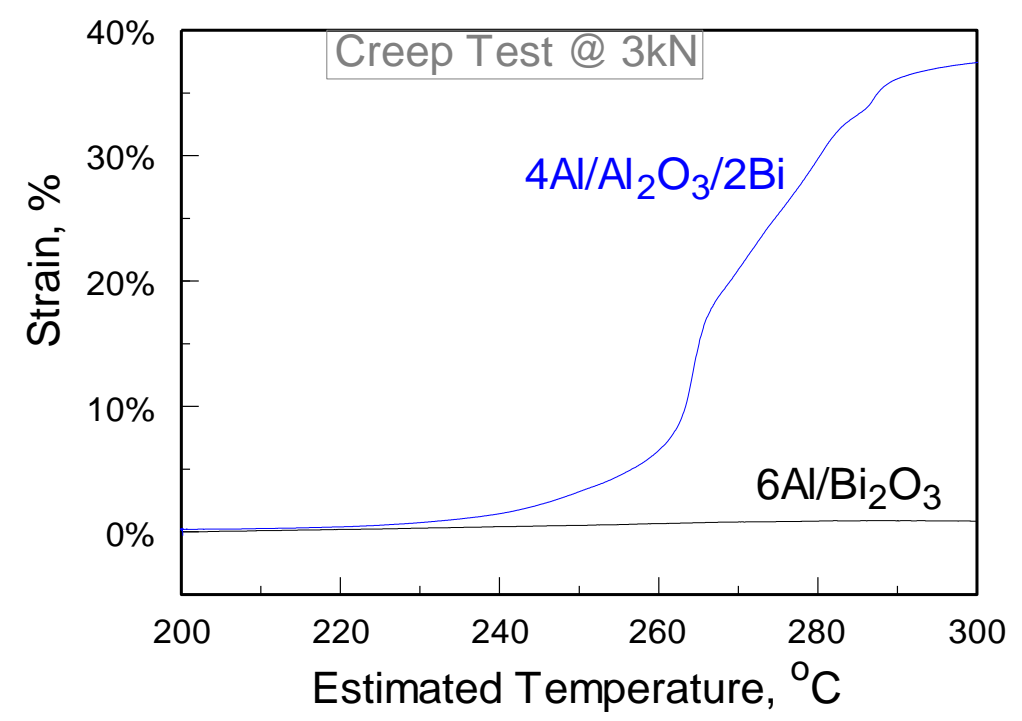

Figure 6. Creep Test of $6 \mathrm{Al} / \mathrm{Bi}_{2} \mathrm{O}_{3}$ and $4 \mathrm{Al} / \mathrm{Al}_{2} \mathrm{O}_{3} / 2 \mathrm{Bi}$. 

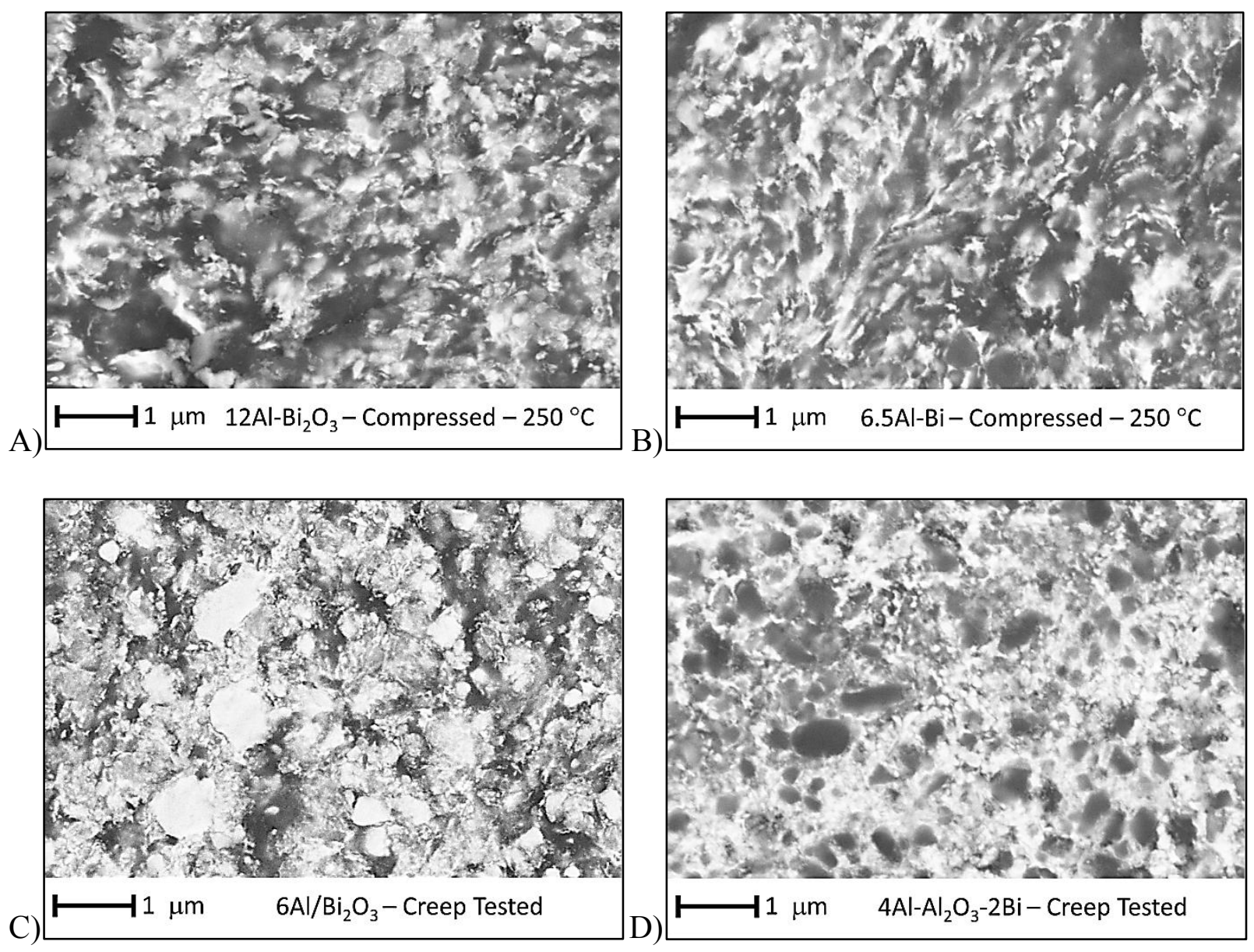

Figure 7. Backscattered electron cross-sectional SEM image of samples annealed at $300{ }^{\circ} \mathrm{C}$ for 5 days before compression and creep tested using Instron (A) $12 \mathrm{Al} / \mathrm{Bi}_{2} \mathrm{O}_{3}$ metal-metal oxide nanocomposite compression tested at $250{ }^{\circ} \mathrm{C}$ (B) $6.5 \mathrm{Al} / \mathrm{Bi}$ metal-metal composite compression tested at $250{ }^{\circ} \mathrm{C}(\mathrm{C}) 6 \mathrm{Al} / \mathrm{Bi}_{2} \mathrm{O}_{3}$ metal-metal oxide nanocomposite creep tested from $200-300{ }^{\circ} \mathrm{C}$ at $3 \mathrm{kN}$. (D) $4 \mathrm{Al} / \mathrm{Al}_{2} \mathrm{O}_{3} / 2 \mathrm{Bi}$ creep tested from $200-300{ }^{\circ} \mathrm{C}$ at $3 \mathrm{kN}$. 
Table 1. Peak onset temperature and energy stored for the prepared materials. For the measurements, annealed samples were cooled to $50{ }^{\circ} \mathrm{C}$ and re-heated to $300{ }^{\circ} \mathrm{C}$, above the melting point of $\mathrm{Bi}$.

\begin{tabular}{|c|c|c|c|c|}
\hline \multirow{2}{*}{ Material } & \multirow{2}{*}{ Annealing conditions } & \multirow{2}{*}{ Peak onset, ${ }^{\circ} \mathrm{C}$} & \multicolumn{2}{|c|}{ Energy Stored, J/g } \\
\hline & & & Actual & Expected \\
\hline \multirow{2}{*}{$12 \mathrm{Al} / \mathrm{Bi}_{2} \mathrm{O}_{3}$} & $550{ }^{\circ} \mathrm{C}$ for $6 \mathrm{hrs}$ & 256.9 & 26.40 & 27.5 \\
\hline & $300^{\circ} \mathrm{C}$ for $64 \mathrm{hrs}$ & 253.4 & 22.39 & 27.5 \\
\hline \multirow[t]{2}{*}{$6.5 \mathrm{Al} / \mathrm{Bi}$} & $550{ }^{\circ} \mathrm{C}$ for $6 \mathrm{hrs}$ & 264.4 & 31.74 & 28.3 \\
\hline & $300^{\circ} \mathrm{C}$ for $64 \mathrm{hrs}$ & 264.2 & 29.40 & 28.3 \\
\hline
\end{tabular}




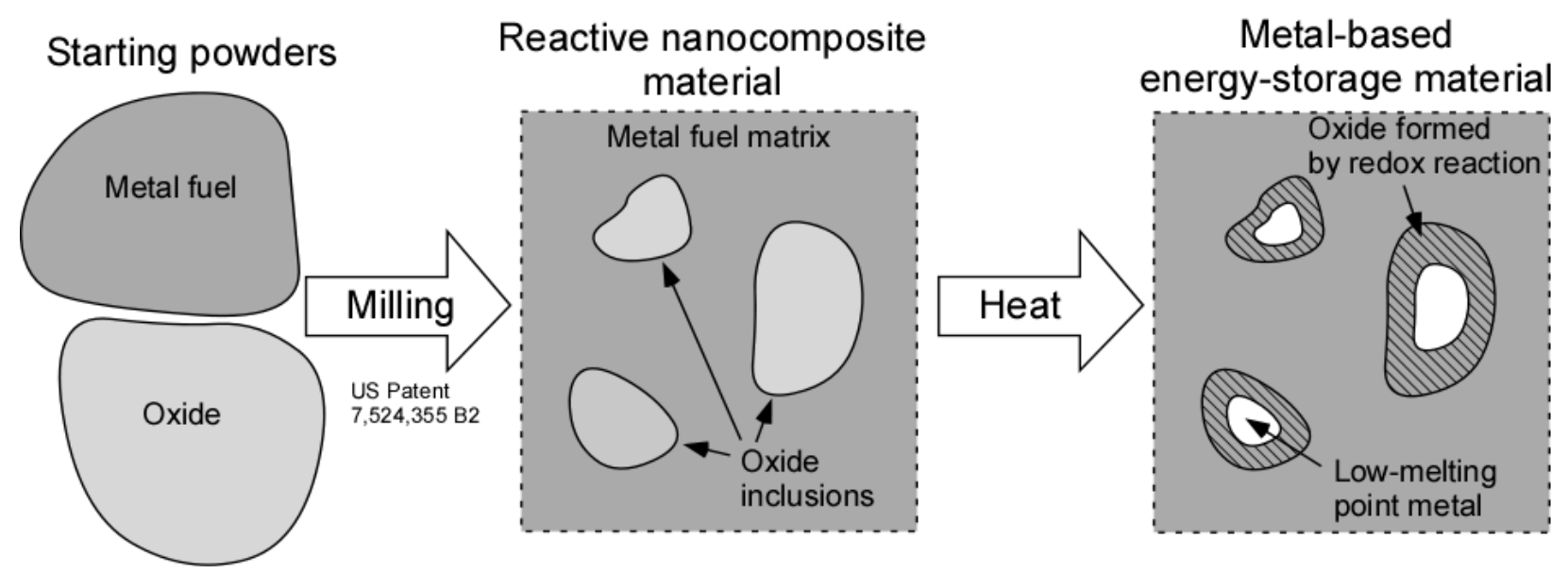

